\title{
Phenol Removal from Aqueous Solution by Adsorption Technique Using Coconut Shell Activated Carbon
}

\author{
Zhi Hoong Ho ${ }^{1 *}$, Liyana Amalina Adnan² \\ ${ }^{1}$ Department of Civil and Construction Engineering, Faculty of Engineering and Science, Curtin University Malaysia, CDT \\ 250, Miri 98009, Malaysia \\ ${ }^{2}$ Kolej GENIUS Insan, Universiti Sains Islam Malaysia, Bandar baru Nilai, Nilai 71800, Malaysia \\ *Correspondence: zhihoong.ho@gmail.com
}

SUBMITTED: 28 September 2021; REVISED: 14 October 2021; ACCEPTED: 15 October 2021

\begin{abstract}
Adsorption is one of the simplest techniques with low economic requirements. Coconut shell is an abundant agriculture waste which is inexpensive and easy to be obtained in Malaysia. This agriculture waste was transformed to activated carbon via $600^{\circ} \mathrm{C}$ of carbonization and zinc chloride activation. The ability of coconut shell-based activated carbon to remove phenolic compounds from aqueous solutions was evaluated. From the experiment, the equilibrium time for the adsorption of phenol onto coconut shell-based activated carbon is 120 minutes. The effect of the operating parameters, such as contact time, initial concentration, agitation speed, adsorbent dosage, and $\mathrm{pH}$ of the phenolic solution were studied. Adsorption kinetics models (pseudo-first-order, pseudo-second-order, and Elovich equation) and isotherm models (Langmuir, Freundlich, Temkin, and Dubinin-Radushkevich) were used to fit the experimental data.Pseudo-second-order was found to be the best fitted kinetics model to describe the adsorption of phenol on coconut shell-based activated carbon. While the equilibrium experiment data was well expressed by the Temkin isotherm model, The maximum adsorption capacity is determined as $19.02 \mathrm{mg} / \mathrm{g}$, which is comparatively lower than the previous research. Meanwhile, $92 \%$ of removal efficiency was achieved by a dosage of $10 \mathrm{~g} / \mathrm{L}$. Meanwhile, the adsorption of phenol by activated carbon was more favorable under acidic conditions. The favourable isotherm behavior was indicated by the dimensionless separation factor. The functional group and compound class of activated carbon before and after the experiment were determined through the analysis of Fourier-transform infrared (FTIR) spectroscopy.
\end{abstract}

KEYWORDS: Agricultural waste; synthetic dyes; adsorption; dye water.

\section{Introduction}

Phenol was first extracted from coal tar by the German chemist, Friedlieb Ferdinand Runge, in 1834. It is known as an aromatic compound with a benzene ring structure. It forms a hygroscopic crystalline solid when under pressure at room temperature. Pure phenol presents itself in white solid form, but it is mostly colored when impurities exist. It can be dissolved in hydrocarbons such as benzene, as well as several polar solvents, for example, ethyl alcohol and ether. While, it behaves as a weak acid which can only partially dissociate in water. Liquid 
phenol can damage coatings, rubber and some forms of plastic. Hot liquid phenol may destroy aluminum, lead, zinc and magnesium [1,2]. Currently, phenol removal can be executed by the separation and destruction method. The technologies of the separation method consist of steam distillation, liquid-liquid extraction with various solvents, adsorption, membrane pervaporation, and membrane-based solvent extraction. On the other hand, the destruction method is carried out through total oxidation of phenol by air or oxygen in water solution, wet oxidation with chemical oxidants, electrochemical oxidation, photocatalytic oxidation, supercritical water gasification, degradation of phenol by electron discharges, biochemical degradation, combination of degradation methods and other techniques for providing energy for phenol destruction [3]. Adsorption is a fast, cost-effective, and universal technique among numerous water treatment technologies. The adsorption technique for water purification consists of a batch process and a column operation [4].

The adsorption technique is widely used in purifying and diluting the concentration of pollutants in waste. Activated carbon (AC) is the most commonly used adsorbent for wastewater treatment [5]. Activated carbon has been prioritized as the adsorbent for recycling and purification since the establishment of adsorption in 1940s. Agriculture based activated carbon has a much lower cost compared to commercial activated carbon. Varies of agriculture waste had been successfully transformed into activated carbon, for instance, coir pith, waste wood, orange peel, bagasse, coffee husk, pine cone, sunflower seed hull, coconut tree, hazelnut husks, rice hulls, oil palm shell, coconut husk and pine-fruit shell [6]. Carbonization is the process that removes non-carbon elements through pyrolytic decomposition, such as oxygen and hydrogen in gaseous state. However, the adsorption capacity of the resulting carbonized product is still low, thus, activation is required to improve the adsorption capability of the carbonized product, by transforming it into activated carbon [7]. The objective of the research was to investigate the adsorption capacity of coconut shell activated carbon for phenol removal. The isotherm model, kinetic studies, and functional groups played a main role in adsorption process was also determined.

\section{Materials and Methods}

\subsection{Dye solution and adsorbent.}

Phenol powder is bought from Sigma Aldrich (M) Sdn. Bhd. and stored at temperature range of $2-8^{\circ} \mathrm{C}$ in refrigerator. It is dissolved in distilled water for preparation of phenolic solution. The chemical and physical properties of phenol is shown in Table 1 . A $100 \mathrm{mg} / \mathrm{L}$ of phenolic stock solution is prepared by adding $0.1 \mathrm{~g}$ of phenol powder into $1 \mathrm{~L}$ of distilled water. The mixture of phenol powder and distilled water is then stirred by using magnetic stirrer to ensure the phenol powder is fully dissolved in the distilled water. This stock solution is prepared under ambient temperature. Establishment of calibration curve requires 5 sets of phenolic solution with different concentration. The coconut shell was collected from a local market and cleaned by tap water to remove the dirt. The adsorbent was ground and dried in the oven at $105^{\circ} \mathrm{C}$ for 24hours and sieved through $600 \mu \mathrm{m}$ sieve to obtain a similar average size of the adsorbent powder and stored it in an airtight container at room temperature. The activated carbon is made from coconut shell under $600^{\circ} \mathrm{C}$ carbonization and zinc chloride chemical activation. 
Table 1. Chemical and physical properties of phenol.

\begin{tabular}{ll}
\hline & \\
Formula & 94.11 \\
& 40.9 \\
Molecular weight $(\mathrm{g} / \mathrm{mol})$ & 181.75 \\
$\mathrm{~T}_{\operatorname{melt}}\left({ }^{\circ} \mathrm{C}\right)$ & $9.3 \mathrm{~g}_{\text {pheno }} / 100 \mathrm{ml}_{\text {water }}$ \\
$\mathrm{T}_{\mathrm{eb}}\left({ }^{\circ} \mathrm{C}\right)$ & 9.89. \\
$\mathrm{Water}_{\text {atu solubility (r.t.) }}$ & $270 \mathrm{~nm}$ \\
$\lambda_{\max }$ & 1.7 (lower);8.6 (higher) \\
pKa & \\
Flammability limits in air (vol\%) & \\
\hline
\end{tabular}

\subsection{Batch studies.}

An adsorption experiment was conducted by preparing a $1 \mathrm{~g} / \mathrm{L}$ adsorbent in a $50-\mathrm{ml}$ conical flask. The rubber seal was used to cover each top of the conical flask to prevent any dust particles from polluting the solutions. All conical flasks were put on the rotary shaker at an agitated speed of $100 \mathrm{rpm}$ at room temperature. After filtration using Whatman filter paper, the adsorption capacity of phenol was analyzed by UV-Vis spectrophotometer (Perkin Elmer Lambda $\mathrm{Bio}^{+}$) at $\lambda_{\max } 270 \mathrm{~nm}$. The formulas for both adsorption capacities are shown below:

$q_{t}=\left(\frac{C_{o}-C_{t}}{W}\right) V$

where, $C_{o}(\mathrm{mg} / \mathrm{L})$ and $C_{t}(\mathrm{mg} / \mathrm{L})$ is initial concentration and concentration at particular time of phenolic solution, respectively. $W(g)$ is mass of activated carbon, $V(L)$ is the volume of phenolic solution. A graph of $q_{t}$ vs $t$ is plotted to determine the equilibrium time of adsorption. Various experimental parameters were summarized in Table 2

Table 2. Summarizes for all experiments of batch adsorption.

\begin{tabular}{lcccc}
\hline \multicolumn{1}{c}{ Parameters } & $\begin{array}{c}\text { Initial } \\
\mathbf{p H}\end{array}$ & $\begin{array}{c}\text { Dosage } \\
(\mathbf{g} / \mathbf{L})\end{array}$ & $\begin{array}{c}\text { Agitation } \\
(\mathbf{r p m})\end{array}$ & $\begin{array}{c}\text { Initial Concentration } \\
(\mathbf{m g} / \mathbf{L})\end{array}$ \\
\hline Effect of Initial pH & $3-12$ & 1 & 100 & 10 \\
Effect of Dosage & 7 & $1-6$ & 100 & 10 \\
Effect of Agitation Speed & 7 & 1 & $100-300$ & 10 \\
Effect of Initial Concentration & 7 & 1 & 100 & $10-60$ \\
\hline
\end{tabular}

\subsection{Isotherm and kinetic studies.}

Adsorption isotherm is a measurement of maximum adsorption capacity. An adsorption equilibrium is represented by certain constant values which define the affinity and surface properties of the adsorbent. Freundlich, Langmuir, Temkin and Dubinin-Radushkevich were used to investigate the adsorption isotherm models for phenol removal (Table 3). The Langmuir adsorption isotherm was originally developed to describe the adsorption of activated carbon in the gas-solid-phase to conventionally quantify and differentiate the adsorption performance of various bio-sorbents [8]. It denotes homogeneous adsorption with constant activation energy and enthalpies and no adsorbate transmigration on the adsorbent's surface [9]. The Freundlich adsorption isotherm describes the equilibrium on heterogenous surfaces without assuming monolayer adsorption capacity [10]. Therefore, it is commonly used in adsorption over heterogenous surfaces, especially organic compounds on activated carbon and molecular sieve 
[11]. Temkin isotherm consists of a factor which explicitly considers the interactions between adsorbent and adsorbate. The assumption made is that the adsorption heat of all particles in the layer would decrease linearly due to the adsorbate-adsorbent interaction [12]. The DubininRadushkevich isotherm is an empirical model which begins with a consideration of the adsorption of subcritical steam onto micropore solids following a pore filling mechanism [13]. Generally, it is applied to express the adsorption mechanism on a heterogenous surface with a Gaussian energy distribution $[14,15]$.

Table 3. List of linear form of formulas of isotherm models.

\begin{tabular}{|c|c|c|c|}
\hline Model & Linear form & Plot & References \\
\hline \multirow[t]{4}{*}{ Langmuir } & $\frac{C_{e}}{q_{e}}=\frac{1}{Q_{o} K_{L}}+\frac{C_{e}}{Q_{o}}$ & $\frac{C_{e}}{q_{e}}$ vs $C_{e}$ & {$[8]$} \\
\hline & $\frac{1}{q_{e}}=\frac{1}{Q_{o}}+\frac{1}{Q_{o} K_{L} C_{e}}$ & $\frac{1}{q_{e}}$ vs $\frac{1}{C_{e}}$ & \\
\hline & $q_{e}=Q_{o}-\frac{q_{e}}{K_{L} C_{e}}$ & $q_{e} \operatorname{vs} \frac{q_{e}}{K_{L} C_{e}}$ & \\
\hline & $\frac{q_{e}}{C_{e}}=K_{L} Q_{o}-K_{L} q_{e}$ & $\frac{q_{e}}{C_{e}}$ vs $q_{e}$ & \\
\hline Freundlich & $\log q_{e}=\log K_{F}+\frac{1}{n} \log C_{e}$ & $\log q_{e}$ vs $\log C_{e}$ & [10] \\
\hline Temkin & $q_{e}=\frac{R T}{b_{T}} \ln A_{T}+\left(\frac{R T}{b_{T}}\right) \ln C_{e}$ & $q_{e} \mathrm{vs} \ln C_{e}$ & {$[12]$} \\
\hline Dubinin-Radushkevich & $\ln q_{e}=\ln q_{s}-k_{a d} \varepsilon^{2}$ & $\ln q_{e}$ vs $\varepsilon^{2}$ & {$[13]$} \\
\hline
\end{tabular}

where, $Q_{o}(\mathrm{mg} / \mathrm{g})$ is the monolayer adsorption capacity, $K_{L}(\mathrm{~L} / \mathrm{mg})$ is the Langmuir constant related to adsorption energy, $C_{e}(\mathrm{mg} / \mathrm{L})$ is the concentration of absorbate at equilibrium, $C_{0}(m g / L)$ is the initial concentration of phenolic solution, $q_{e}(\mathrm{mg} / \mathrm{g})$ is the adsorption capacity at equilibrium, $K_{F}(m g / g)(m g / L)^{n}$ is Freundlich constant in respect with adsorption capacity of adsorbent, $1 / n$ determines the adsorption intensity, $\frac{R T}{b_{T}}(\mathrm{~J} / \mathrm{mol})$ is Temkin constant in relation to heat of adsorption, $A_{t}(\mathrm{~L} / \mathrm{g})$ is equilibrium binding constant in respect with maximum binding energy, $R$ is universal gas constant with a value of $8.314 \mathrm{~J} / \mathrm{mol} K, T(K)$ is the absolute solution temperature, and $q_{s}(\mathrm{mg} / \mathrm{g})$ is the theoretical adsorption capacity at saturation, $k_{a d}$ is the Dubinin isotherm constant.

For kinetic models, the adsorption process was analyzed with the pseudo-first-order, pseudo-second-order, and Elovich (Table 4). The pseudo-first-order kinetic model is widely used for estimation of sorption kinetics. The pseudo-second-order equation is defined as the sorption capacity of adsorption in the solid phase. Contrary to pseudo-first-order, it agrees with the adsorption mechanism's being a rate-limiting step and determines the behavior of adsorption over the entire range. The Elovich equation is considered the most useful model for fitting into chemisorption.

Table 4. List of linear form of formulas and plots of kinetics models.

\begin{tabular}{llll}
\hline Model & Linear form & Plot & References \\
\hline Pseudo-first-order & $\log \left(q_{e}-q_{t}\right)=\log q_{e}-\frac{k_{1}}{2.303} t$ & $\log \left(q_{e}-q_{t}\right)$ vs $t$ & [16] \\
Pseudo-second-order & $\frac{t}{q}=\frac{1}{k_{2} q_{e}^{2}}+\frac{1}{q_{e}} t$ & $\frac{t}{q_{t}} \mathrm{vs} t$ & [17] \\
Elovich & $q_{t}=\left(\frac{1}{b}\right) \ln (a b)+\frac{1}{b} \ln t$ & $q_{t}$ vs $\ln t$ & \\
\hline
\end{tabular}


where $q_{e}(m g / g)$ and $q_{t}(m g / g)$ adsorption capacity at equilibrium and at any time, $t(h)$, $k_{1}(1 / h)$ is the adsorption kinetics rate constant. The linear plot of $\frac{t}{q_{t}}$ against $t$ results a slope of $\frac{1}{q_{e}}$ and intercept of $\frac{1}{k_{2} q_{e}^{2}} . \mathrm{K}_{1}$ is the pseudo-first-order rate constant, $\mathrm{k}_{2}$ is the pseudo-secondorder rate constant, and $\mathrm{t}$ is the contact time with adsorbent ( $\mathrm{min}), a(\mathrm{mg} / \mathrm{g} h)$ is the initial sorption rate, $b(\mathrm{mg} / \mathrm{g})$ is representing the activation energy for chemisorption and expansion of surface coverage, $\left(\frac{1}{b}\right)$ and $\ln (a b)$ are representing the number of sites.

\subsection{FTIR.}

An analysis to determine the functional group of the adsorbents before and after adsorption of phenol was conducted by using Fourier Transform Infrared Spectroscopy (FTIR) (Spectrum one, Perkin Elmer, USA) recorded in the spectral range of $400-4000 \mathrm{~cm}^{-1}$.

\section{Results and Discussion}

\subsection{Batch studies.}

Figure 1 shows the effect of initial concentration, dosage, $\mathrm{pH}$, and agitation speed on the adsorption of phenol by activated carbon. It shows that the adsorption capacity increases from $4.80 \mathrm{mg} / \mathrm{g}$ to $19.02 \mathrm{mg} / \mathrm{g}$ with an increase in initial phenol concentration from $10 \mathrm{mg} / \mathrm{L}$ to 60 $\mathrm{mg} / \mathrm{L}$ (Fig. 1A). This can be justified by the fact that mass transfer driving force increases when the initial concentration of phenol increases, which leads to a high tendency for adsorption [19]. On the contrary, for the lower initial concentration of phenol, the molecules of phenol supplied for adsorption are too small for that dosage of activated carbon. For instance, a certain amount of activated carbon still has extra active vacant sites for adsorption. However, the removal efficiency of adsorption of phenol decreases when the initial concentration increases. Therefore, the active vacant sites of activated carbon are enough to adsorb the low number of phenol molecules [19]. Hence, the percentage of change in concentration is higher for a lower initial concentration of phenol, resulting in a higher percentage of removal efficiency. Meanwhile, for higher initial concentration, the molecules of phenol supplied for adsorption are too saturated at the fixed adsorbent dosage. Thus, saturation is achieved without changing much of the percentage of concentration, resulting in lower removal efficiency. The changing variable is adsorbent dosage, which influences the result of adsorption capacity and removal efficiency. Fig. 1B shows the results of adsorption capacity and removal efficiency affected by different adsorbent dosage, respectively. These experimental results have a similar trend to the effect of initial concentration. The adsorption capacity decreases while the removal efficiency increases when the adsorbent dosage increases. At a higher dosage of activated carbon, the ratio of active vacant sites available to phenol molecules is high. Therefore, the excess sorption sites are extra enough for the limited phenol molecules. Hence, it tends to decrease the concentration of phenol efficiently due to the greater surface area of the adsorbent, resulting in high removal efficiency. While the adsorption capacity is low as the phenol molecules are not saturated enough to use up the vacant sorption sites, The adsorption capacity and phenol removal efficiency decrease with the same behavior when the solution $\mathrm{pH}$ value increases (Fig. $1 \mathrm{C})$. 

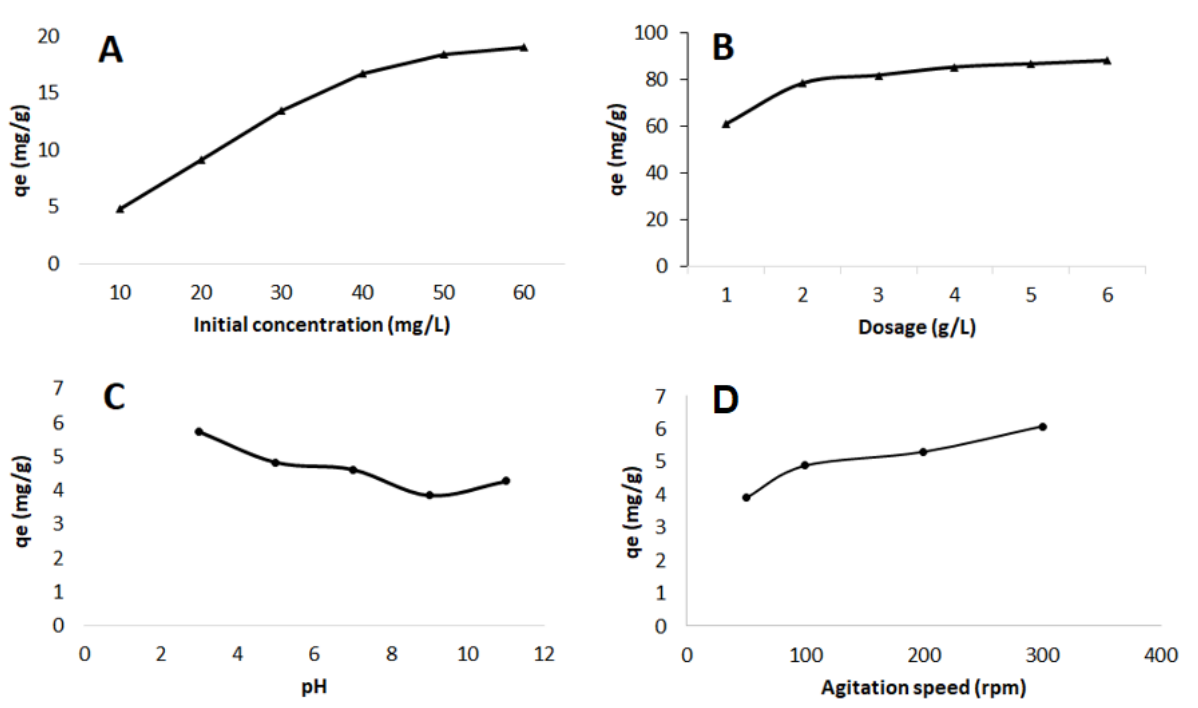

Figure 1. Effect of initial concentration (A), dosage (B), $\mathrm{pH}(\mathrm{C})$, and agitation speed (D) for adsorption of phenol by activated carbon.

In this experiment, the highest removal efficiency is achieved at $\mathrm{pH}$ 3. Phenol is a weak acid compound. Therefore, in an acidic phase with a $\mathrm{pH}$ value lower than $\mathrm{p} K_{a}$, phenol is unable to ionize and has significant dispersion force interactions. high concentration of unionized species of halogenated organic compounds which do not favour the repulsion between phenol molecules and the activated carbon sorption surface. Therefore, the electrostatic forces between adsorption sites and phenol molecules are enhanced [19]. On the contrary, at pH higher than $\mathrm{p} K_{a}$, ionization occurs and induces repulsion forces between surface negative charges and phenolate-phenolate anions [20]. Moreover, the competition between hydroxide ions and the phenol ionic group is reducing the removal efficiency of activated carbon from phenol. In short, the protonated phenolic compound has a higher tendency for adsorption compared to the ionized phenolic compound. There are similar trends reported in adsorption of trichlorophenol using oil palm empty fruit bunch based-activated carbon [19] and coconut shell based-activated carbon [21]. Agitation facilitates effective diffusion of solute ions towards the adsorbent surface by promoting appropriate contact between ions of solute and adsorbent at binding sites. The adsorption capacity and removal efficiency are increasing due to an increase in agitation speed (Fig. 1D). This is due to the enhancement of effective mass transport of phenol ions with great driving force towards an adsorbent vacant site. Higher agitation speeds reduce the diffusion resistance within the reaction [22].

\subsection{Adsorption kinetics.}

In this research, the experimental results for the adsorption of phenol onto coconut shell-based activated carbon are used to plot graphs of three different kinetic models: pseudo-first-order, pseudo-second-order, and Elovich equation, as shown in Fig. 2. The correlation coefficients of the pseudo-first-order and Elovich equations are 0.985 and 0.841 , respectively, which are considered not close to 1. Meanwhile, the pseudo-second-order kinetics model is the best fitted model as it demonstrates the closest value to 1 among all the kinetics models, which is 0.999 . Therefore, this indicates that the pseudo-second-order perfectly describes the adsorption kinetic process. Pseudo-second-order defines the reaction between phenolic compounds and coconut shell-based activated carbon as being dependent on the concentration of both reactants, instead 
of the one reactant assumed by pseudo-first-order. Pseudo-second-order as the best-describing model is agreed to be similar to previous research on the adsorption of trichlorophenol on oil palm empty fruit bunches based on activated carbon [19]. However, pseudo-first order is the best fitted model revealed by Mukherjee et al. for the adsorption of phenol by activated carbon [23].

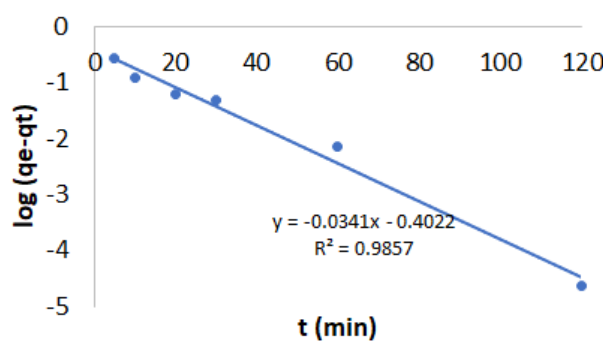

A

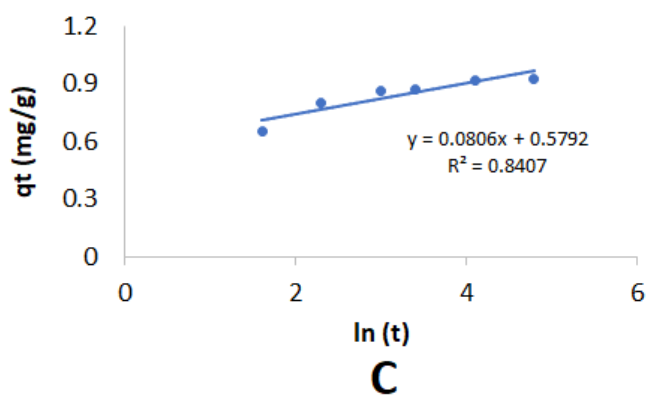

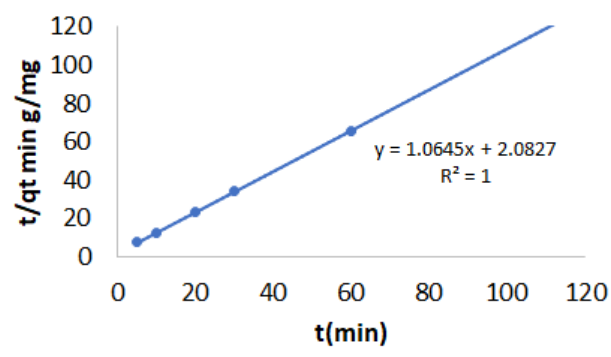

B

Figure 2. Kinetic model for phenol removal: Pseudo-first-order (A), Pseudo-second-order (B), and Elovic (C).

\subsection{Adsorption isotherms.}

Figure 3 shows four different isotherm, Langmuir, Freundlich, Temkin and DubininRadushkevich. The correlation coefficients of Langmuir, Freundlich, Temkin and DubininRadushkevich are $0.940,0.956,0.982$ and 0.975 respectively, which are considered quite close to 1 . Meanwhile, the Temkin model is the best fitted model as it demonstrates the closest value to 1 among all the kinetics models. Therefore, this indicates that pseudo-second-order perfectly describes the adsorption kinetic process. Temkin assumes that all the binding sites are not equal with variation in site quality. Adsorption will only occur at certain sites, preferably the higher energy sites, although there is repulsion at the vacant sites when the neighboring sites are occupied, followed by low-energy sites. The calculated value fromthe Langmuir model is 0.737, which is in between 0 and 1 , which indicates the adsorption of phenol onto coconut shell-based-activated carbon is favorable. The value obtained from the Freundlich isotherm model is below 1, which defines the favorable adsorption condition. Moreover, the correlation value shows that the Freundlich is better than Langmuir in describing the adsorption of phenol on activated carbon. It is agreed by the previous research on the adsorption of trichlorophenol by using oil palm empty fruit bunches based on activated carbon [19], chlorophenol by using surfactant-modified natural zeolite [24], and activated clay [25]. However, there are some reports from previous research which demonstrate that some adsorptions are better represented by the Langmuir model. For instance, adsorption of phenol by using rattan sawdust-based activated carbon [25] and adsorption of trichlorophenol on coconut-shell activated carbon [21]. 

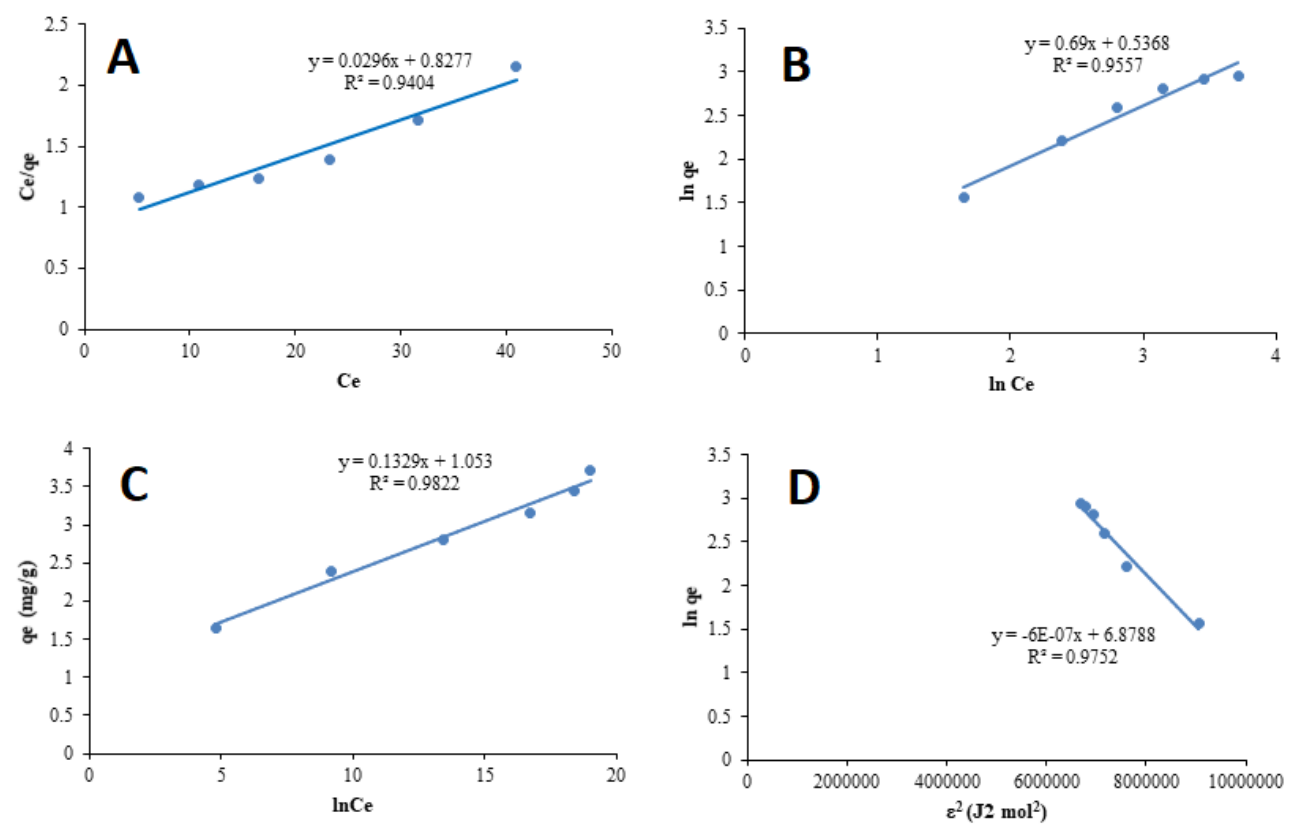

Figure 3. Isotherm model for phenol removal: Freundlich (A), Langmuir (B), Temkin (C), and DubininRadushkevich (D).

\subsection{FTIR analysis.}

The coconut shell-based activated carbon before and after adsorption were analyzed by FTIR. Figure 4 shows the spectrum being absorbed at the surface of activated carbon. The wavenumber obtained corresponds to the bonding of functional groups. Therefore, the functional groups of activated carbon were determined by comparing the FTIR spectra with the IR spectrum (Table 5). It can be seen that the peaks of the spectra have shifted after the experiment. While others disappeared, new peaks formed after adsorption. The functional groups of carboxylic acids are aromatic compounds that remain after experiment. However, new functional groups such as alkane, alkyl aryl ether, alcohols, esters, ethers, alkenes and alkyl halides were found in activate carbon after adsorption. This is due to the exchange of ions between phenol and activated carbon surface functional groups, and it is clearly understood that phenol has hydroxide ions which affect the initial bonding at the surface of activated carbon.
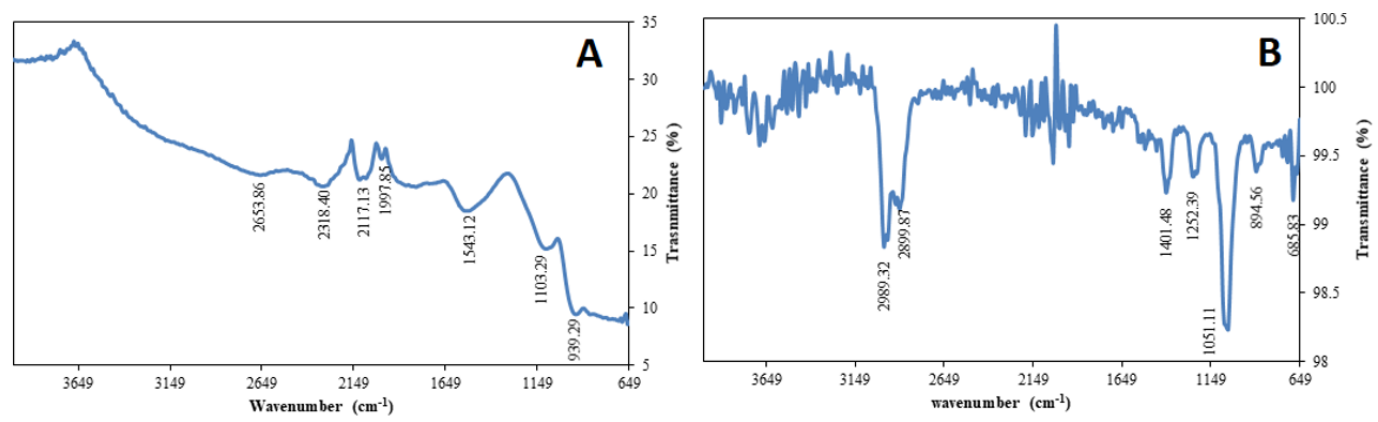

Figure 4. FTIR spectra for coconut shell-based activated carbon: before adsorption (A) and after adsorption (B). 
Table 5. FTIR band of coconut shell- based activated carbon $\left(\mathrm{ZnCl}_{2}\right)$ before and after adsorption.

\begin{tabular}{lll}
\hline Frequency $\left(\mathbf{c m}^{-1}\right)$ & Bond & Functional groups \\
\hline Before adsorption & & \\
2653.86 & O-H stretching & Carboxylic acid \\
$2260-2222$ & C $\equiv$ N stretching & Nitrile \\
2117.13 & C $=$ C stretching & Alkyne \\
1997.85 & C-H bending & Aromatic compound \\
1543.12 & N-O stretching & Nitro compound \\
1103.29 & C-N stretching & Amine \\
939.29 & O-H bending & Carboxylic acid \\
& & \\
After adsorption & & \\
2989.32 & C-H stretching & Alkane \\
2899.87 & C-H stretching & Alkane \\
1401.48 & C-C stretching (in ring) & Aromatic compound \\
1252.39 & C-O stretching & Alkyl aryl ether \\
1051.11 & C-O stretching & Alcohols, carboxylic acids, esters, ethers \\
894.56 & C-H bending & Alkenes \\
685.83 & C-Br stretching & Alkyl halides \\
\hline
\end{tabular}

\section{Conclusion}

The maximum adsorption capacity is $19.02 \mathrm{mg} / \mathrm{g}$, which is considered very low compared to the previous work done by other researchers. Furthermore, raising the starting concentration, contact time, and agitation speed while decreasing the adsorbent dosage increases the adsorption capacity of activated carbon. It has been discovered that an acidic phenol solution with a low $\mathrm{pH}$ value is better for being adsorbed onto activated carbon. The adsorption of phenol on activated carbon is best represented by a pseudo-second-order kinetic model, according to adsorption kinetics studies. While adsorption isotherm research has revealed that the Temkin isotherm model is the best fit for modelling the equilibrium adsorption of phenol to activated carbon.

\section{Acknowledgements}

The authors thank Curtin University Malaysia for facilitating this work. The collaboration from Universiti Sains Islam Malaysia is highly appreciated.

\section{Conflicts of Interest}

The authors declare no conflict of interest.

\section{References}

[1] Catino, S.C.; Farris, E. (1985). Concise encyclopedia of chemical technology. New York: John Wiley and Sons.

[2] Gami, A.A.; Shukor, M.Y.; Khalil, K.A.; Dahalan, F.A.; Khalid, A.; Ahmad, S.A. (2014). Phenol and its toxicity. Journal of Environmental Microbiology and Toxicology, 2, 11-24.

[3] Busca, G.; Berardinelli, S.; Resini, C.; Arrighi, L (2008). Technologies for the removal of phenol from fluid streams: a short review of recent developments. Journal of Hazardous Materials, 160, 265-288. https://doi.org/10.1016/j.jhazmat.2008.03.045.

[4] Ali, I.; Gupta, V.K. (2006). Advances in water treatment by adsorption technology. Nature Protocols 1, 2661. https://doi.org/10.1038/nprot.2006.370.

[5] Radovic, L.R.; Moreno-Castilla, C.; Rivera-Utrilla, J. (2001). Carbon materials as adsorbents in aqueous solutions. Chemistry and Physics of Carbon, 27, 227-406.

[6] Aljeboree, A.M.; Alshirifi, A.N.; Alkaim, A.F. (2017). Kinetics and equilibrium study for the adsorption of textile dyes on coconut shell activated carbon. Arabian Journal of Chemistry, 10, S3381-S3393. https://doi.org/https://doi.org/10.1016/j.arabjc.2014.01.020. 
[7] Mozammel, H.M.; Masahiro, O.; Bhattacharya, S.C. (2002). Activated charcoal from coconut shell using $\mathrm{ZnCl} 2$ activation. Biomass and Bioenergy, 22, 397-400. https://doi.org/10.1016/S0961-9534(02)00015-6.

[8] Langmuir, I. (1916). The constitution and fundamental properties of solids and liquids. Part I. Solids. Journal of the American Chemical Society, 38, 2221-2295. https://doi.org/10.1021/ja02268a002.

[9] Perez-Marin, A.B.; Meseguer Zapata, V.; Ortuno, J.F.; Aguilar, M.; Sáez, J.; Lloréns, M. (2007). Removal of cadmium from aqueous solutions by adsorption onto orange waste. Journal of Hazardous Materials, 139, 122-131. https://doi.org/10.1016/j.jhazmat.2006.06.008.

[10] Freundlich, H.M.F. (1906). Adsorption in solids. Journal of Physical Chemistry, 57, 385-470.

[11] Foo, K.Y.; Hameed, B.H. (2010). Insights into the modeling of adsorption isotherm systems. $\begin{array}{llll}\text { Chemical Engineering } & \text { Journal, }\end{array}$ https://doi.org/https://doi.org/10.1016/j.cej.2009.09.013.

[12] Temkin, M.I. (1940). Kinetics of ammonia synthesis on promoted iron catalysts. Acta physiochim. URSS, 12, 327-356.

[13] Dubinin, M.M. (1947). The equation of the characteristic curve of activated charcoal. Proceedings of the Academy of Sciences, Physical Chemistry Section, 55, 331.

[14] Günay, A.; Arslankaya, E.; Tosun, I. (2007). Lead removal from aqueous solution by natural and pretreated clinoptilolite: adsorption equilibrium and kinetics. Journal of Hazardous Materials, 146, 362-371. https://doi.org/10.1016/j.jhazmat.2006.12.034.

[15] Dabrowski, A. (2001). Adsorption - from theory to practice. Advances in Colloid and Interface Science, 93, 135-224. https://doi.org/10.1016/S0001-8686(00)00082-8.

[16] Lagergren, S. (1898). Zur theorie der sogenannten adsorption geloster stoffe. Kungliga Svenska Vetenskapsakademiens. Handlingar 24, 1-39.

[17] Ho, Y.S.; McKay, G. (1998). The kinetics of sorption of basic dyes from aqueous solution by sphagnum moss peat. The Canadian Journal of Chemical Engineering, 76, 822-827. https://doi.org/10.1002/cjce.5450760419.

[18] Zeldowitsch, J. (1934). Über den mechanismus der katalytischen oxydation von $\mathrm{CO}$ an $\mathrm{MnO}_{2}$. Acta Physicochemistry, 1, 364-449.

[19] Tan, I.A.W.; Ahmad, A.L.; Hameed, B.H. (2009). Adsorption isotherms, kinetics, thermodynamics and desorption studies of 2,4,6-trichlorophenol on oil palm empty fruit bunchbased activated carbon. Journal of Hazardous Materials 164, 473-482. https://doi.org/https://doi.org/10.1016/j.jhazmat.2008.08.025.

[20] Moreno-Castilla, C. (2004). Adsorption of organic molecules from aqueous solutions on carbon materials. Carbon, 42, 83-94. https://doi.org/10.1016/j.carbon.2003.09.022.

[21] Radhika, M.; Palanivelu, K. (2006). Adsorptive removal of chlorophenols from aqueous solution by low cost adsorbent-Kinetics and isotherm analysis. Journal of Hazardous Materials, 138, 116-124. https://doi.org/10.1016/j.jhazmat.2006.05.045.

[22] Abussaud, B.; Asmaly, H.A.; Ihsanullah; Saleh, T.A.; Gupta, V.K.; Laoui, T.; Atieh, M.A. (2016). Sorption of phenol from waters on activated carbon impregnated with iron oxide, aluminum oxide and titanium oxide. Journal of Molecular Liquids, 213, 351-359. https://doi.org/https://doi.org/10.1016/j.molliq.2015.08.044.

[23] Mukherjee, S.; Kumar, S.; Misra, A.K.; Fan, M. (2007). Removal of phenols from water environment by activated carbon, bagasse ash and wood charcoal. Chemical Engineering Journal, 129, 133-142. https://doi.org/10.1016/j.cej.2006.10.030.

[24] Kuleyin, A. (2007). Removal of phenol and 4-chlorophenol by surfactant-modified natural zeolite. Journal of Hazardous Materials $144 \quad$ (1-2): 307-315. https://doi.org/10.1016/j.jhazmat.2006.10.036.

[25] Hameed, B.H. (2007). Equilibrium and kinetics studies of 2, 4, 6-trichlorophenol adsorption onto activated clay. Colloids and Surfaces A: Physicochemical and Engineering Aspects, 307, 45-52. https://doi.org/10.1016/j.colsurfa.2007.05.002.

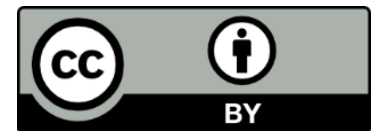

(C) 2021 by the authors. This article is an open access article distributed under the terms and conditions of the Creative Commons Attribution (CC BY) license (http://creativecommons.org/licenses/by/4.0/). 